\title{
PRESERVAÇÃO E EXCLUSÃO: PROJETO DE HABITAÇÃO DE INTERESSE SOCIAL PARA A COMUNIDADE DA GAMBOA DE BAIXO COMO INSTRUMENTO DE LUTA
}

\section{PRESERVACIÓN Y EXCLUSIÓN: PROYECTO DE VIVIENDA DE INTERÉS SOCIAL PARA LA COMUNIDAD DE GAMBOA DE BAIXO COMO HERRAMIENTA DE LUCHA}

\section{PRESERVATION AND EXCLUSION: HOUSING PROJECT OF SOCIAL INTEREST FOR THE COMMUNITY OF GAMBOA DE BAIXO AS A TOOL FOR FIGHTING}

\section{ZANOLI, FABRÍCIO}

Arquiteto e Urbanista, Mestre pelo PPGAU/UFBA, Especialista em Assistência Técnica em Habitação e Direito a Cidade, UFBA. E-mail: fabriciozanoli@gmail.com

\section{IVO, ANY BRITO LEAL}

Arquiteta, Doutora pelo PPGAU/UFBA, Profa. FAUFBA. E-mail: anyivo@gmail.com

\section{INTRODUÇÃO}

Salvador vista da Baía de Todos os Santos apresenta a divisão morfológica entre cidade baixa e alta expressa pela falésia verde. Esse frontispício constituiu uma muralha natural para o mar e atualmente é ocupado, em grande parte, por prédios de alto padrão, ocupações históricas, casarões antigos e ocupações simples como a Gamboa de Baixo. Essa comunidade pesqueira reside há várias décadas no entorno da Bateria de São Paulo, também conhecida como Forte de São Paulo da Gamboa, tombado pelo IPHAN em 1938. O Forte dividia os pequenos portos das Vacas e Gamboa - áreas pesqueiras desde o início do século XIX, segundo os registros dos pescadores da Bahia no século XIX (PORTELA, 2012).

A Gamboa de Baixo, além de estar em uma área de intensa especulação imobiliária, está vinculada a diferentes níveis da administração pública como IPHAN, União, Exército e Prefeitura, com diferentes legislações. Essas diversas competências, entre outros fatores, contribuem para uma gestão pública ineficiente, seguida de intervenções urbanas desconectadas, chegando a atual judicialização pelo Ministério Público pela falta de restauro do Forte de São Paulo.

As intervenções públicas iniciam-se em 1950, com a construção da Avenida Lafayete Coutinho, conhecida como Avenida Contorno, seguida por intervenções de saneamento, pavimentação e melhoria habitacional na comunidade, realizadas pela CONDER ${ }^{1}$ em 1990, e em 2001 pela construção do empreendimento vizinho de alto padrão, Morada dos Cardeais, que retirou algumas casas. Em outubro de 2007, a Superintendência do Patrimônio da União, SPU, proprietária da área de borda de maré, cedeu ao Município de Salvador a propriedade da área ocupada, objetivando a regularização, o que ainda não se realizou (PERRY e CAMINHA, 2008).

Nesse sentido o Ministério Público Federal instaura, em 2009, a ação civil pública n.ำ 2009.33.00.011447-9, contra o IPHAN, o Município de Salvador e SPU, requerendo a implementação das medidas necessárias para o restauro do Forte de São Paulo e solução da ocupação irregular da área, determinando a realocação dos moradores e a regularização fundiária.

Em 2013, através do PAC Cidades Históricas² , o IPHAN licita um projeto de restauro para instalação da sede dos Escoteiros do Mar no Forte de São Paulo. O projeto proposto não foi em momento algum discutido ou apresentado aos ocupantes ou moradores da fortificação, gerando, assim um contra movimento de resistência da comunidade, em relação à tentativa de retirada das famílias do Forte.

Em 2014, inicia-se um processo de assistência técnica, promovida por meio do Curso de Especialização em Habitação e Direito à Cidade, na modalidade Residência Profissional em Arquitetura, Urbanismo e Engenharia (Residência AU+E/UFBA), assumindo o desenvolvimento de um projeto de habitação social para possível

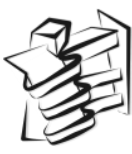


realocação das famílias ocupantes do Forte, em função do restauro previsto, a serem localizadas em área indicada na própria comunidade, conforme demanda levantada pela Associação Amigos de Gegê de Moradores da Gamboa de Baixo, projeto esse apresentado neste artigo.

\section{A RESIDÊNCIA PROFISSIONAL NA GAMBOA DE BAIXO, DA TEORIA AO CAMPO}

O assessoramento técnico iniciado em $2014^{3}$, com a equipe dos Residentes Profissionais do referido curso de especialização atuantes na comunidade da Gamboa de Baixo teve como princípio o respeito e fortalecimento do protagonismo dos moradores. Para tanto foi discutido um plano de trabalho de acompanhamento do grupo, incluindo as reuniões institucionais, produção de documentos técnicos, organização de oficinas e mobilização social para sistematizar as demandas apresentadas pela Associação. Assim, foram criadas esferas para participação dos Residentes, preservando momentos internos da comunidade e suas instâncias decisórias.

A metodologia de trabalho apresentada então visava a participação direta dos moradores, realizando-se para isso oficinas, que viabilizaram documentos técnicos, produção coletiva de mapas, discussão das ações dos Residentes em todas as esferas de participação que envolvesse a comunidade, assim como uma maior aproximação dos moradores com a universidade. A Associação apresentou diversas frentes de trabalho nas quais foram elencadas duas ações possíveis de realização no cronograma previsto, dentre essas a proposta para a regularização fundiária, desenvolvida pelo Residente-urbanista José Aloir e o projeto de realocação dos ocupantes do Forte de São Paulo, proposta em tela. Esses deveriam ser projetos complementares entre si e integrados à melhoria urbana da área, devendo-se iniciar os trabalhos por essas duas propostas. As demais propostas apresentadas foram trabalhadas em parceria com outros membros de movimentos sociais participantes, na busca constante de novos parceiros que permitissem o fortalecimento da Associação e, em consequência, da comunidade.

Figura 1: Vias e serviços identificados na oficina "Descobrindo a Gamboa”, elaborada com os moradores

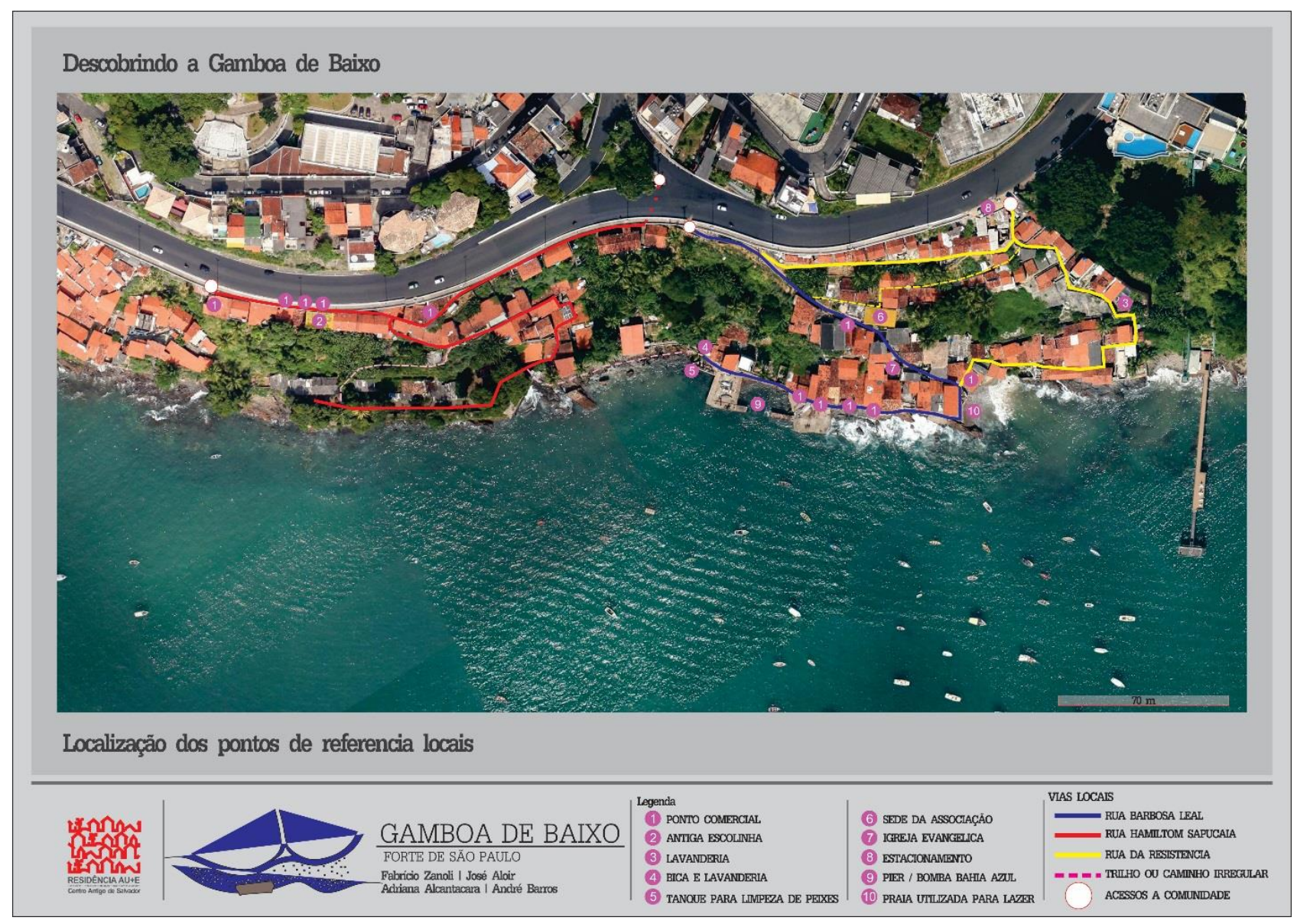

Fonte: Elaboração do autor do projeto (ZANOLI, 2015) GOOGLE. Base Google Earth. Version 7. Salvador-BA. 


\section{O Forte de São Paulo e a proposta para realocação de moradores}

Após o primeiro encontro dos Residentes com os ocupantes do Forte, elaborou-se um calendário de reuniões de ações necessárias. $O$ assessoramento esclareceu que o projeto de arquitetura não significaria a solução das questões e conflitos postos, mas consistia em instrumento de mediação, na discussão com os órgãos e agentes públicos envolvidos, visando a demonstração da real possibilidade de relocação das famílias no próprio bairro - o que até então era descartado nas ações do Estado.

Um questionário foi aplicado conjuntamente com membros da Associação para conhecimento do real número de famílias que residiam no Forte, além da caracterização dos espaços habitados e a vontade de permanência. Identificou-se a coabitação familiar em quase todos os domicílios demarcados no Forte, assim como problemas de saneamento e insalubridade devidos principalmente à ausência de sanitários. A instabilidade das edificações históricas com o desgaste do tempo, mescladas com improvisos construtivos foi outro problema identificado, dentre as, aproximadamente, 12 moradias do Forte, sendo que duas estão em bom estado de conservação, sendo inteiramente adaptado com novos materiais. Houve também unanimidade pela vontade em permanecer na comunidade, seja pela centralidade e facilidades de morar no centro ou pela atividade pesqueira e trabalhos consolidados.

Os terrenos disponíveis identificados, as propostas arquitetônicas e plantas técnicas foram apresentados aos moradores para avaliação coletiva e comparadas às residências existentes na comunidade, facilitando o entendimento do projeto, suas dimensões e escala. Foi elaborado um pré-dimensionamento e avaliação dos potencias construtivos dos terrenos, o que permitiu quantificar o número de habitações do projeto, assim como o grau de dificuldade construtiva.

Figura 2: Aproximações com o Forte de São Paulo e com moradores
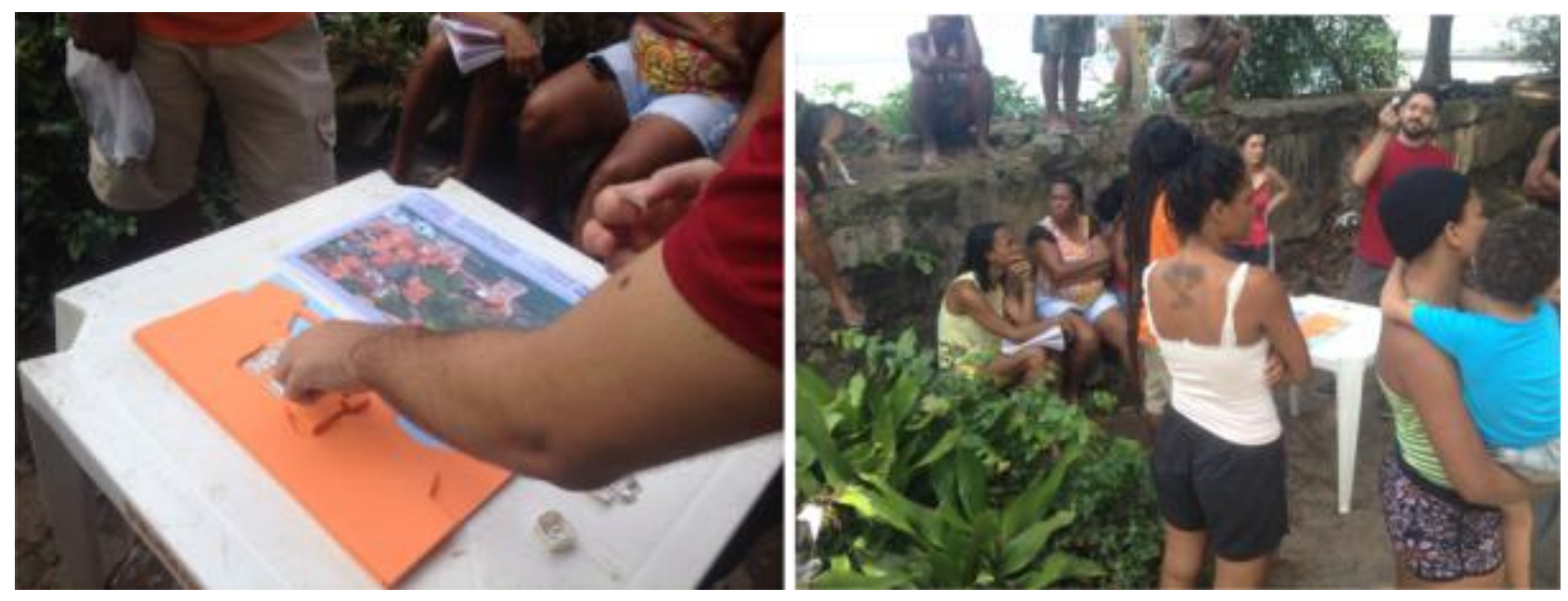

Fonte: Fotos dos autores de projetos para Gamboa de Baixo (ZANOLI, 2015; e ARAÚJO NETO, 2015)

As reuniões com os moradores do Forte seguiram durante todo o ano de 2014, com visitas constantes, o que possibilitou entender o uso do espaço, assim como subsidiou a compatibilização dos usos indicados pela Associação e os usos reais locais. Adotou-se conceitos e métodos etnográficos definidos por Santos (1985) para identificação das formas de interações sociais entre espaço construído, habitações, lazer e trabalho.

A entrada do Forte é ocupada pela maior casa, com três pavimentos e vigas de concreto expostas, logo após um pátio com árvores de grande porte se abre, local do antigo canhão "Vovô" - um dos maiores de Salvador, realocado para o quartel general da Mouraria. A proximidade das portas nas edificações ocupadas do centro do terrapleno proporciona uma intensa interação social, com bancos improvisados em pedras, onde os idosos conversam e pescadores trabalham com seus baldes e redes, que completam a paisagem. A casa principal do Forte é a residência de Dona Rosa, considerada a mais antiga ocupante, com 90 anos, residindo no local há mais de 60 anos. Foi levantado um total de 18 núcleos familiares, somando aproximadamente 37 moradores no interior imediato do Forte de São Paulo. 
Figura 3: Aproximações com o Forte de São Paulo e reunião com moradores

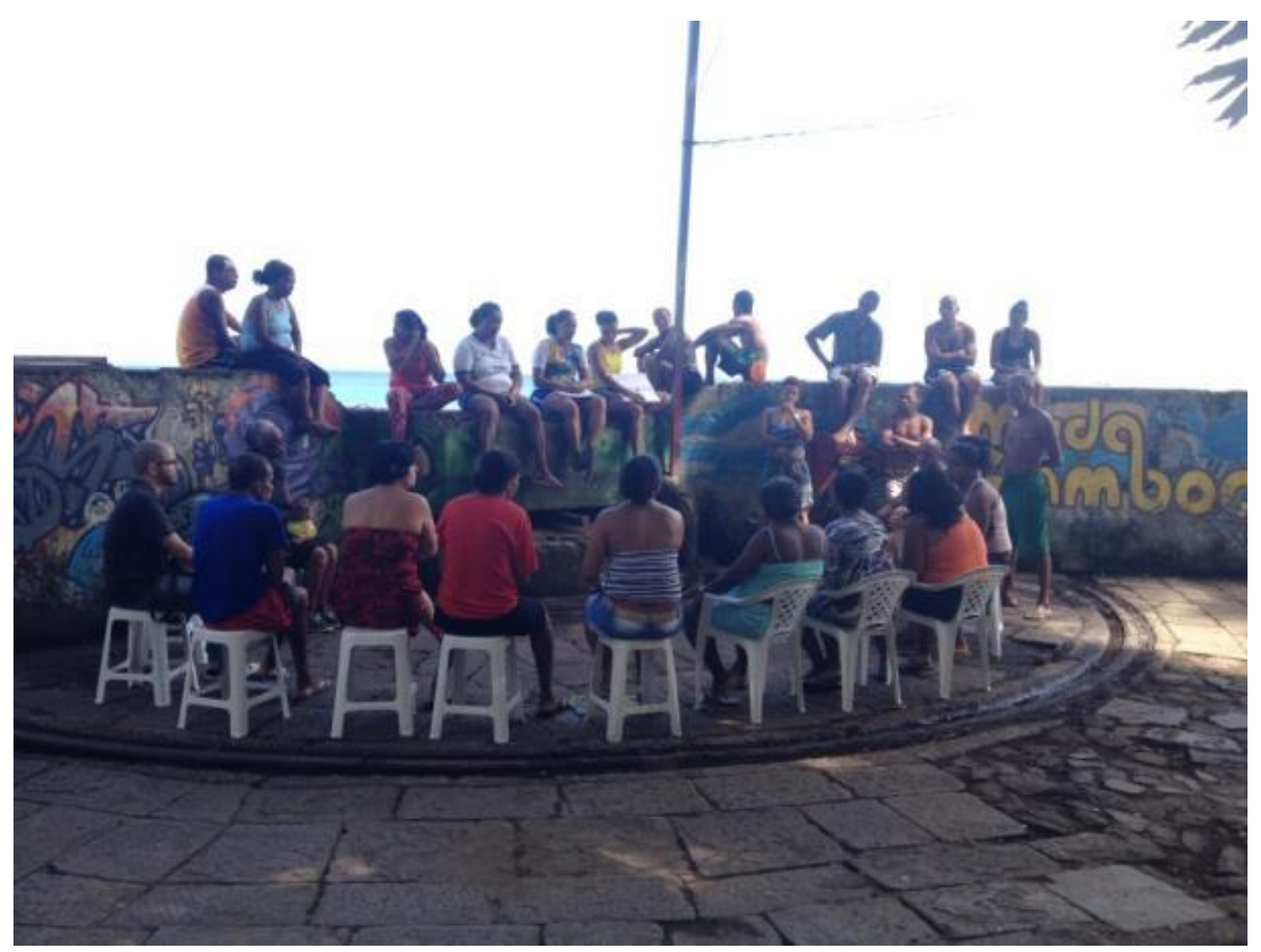

Fonte: Fotos dos autores de projetos para Gamboa de Baixo (ZANOLI, 2015) e (ARAÚJO NETO, 2015)

Figura 4: Usos e tipologias identificadas

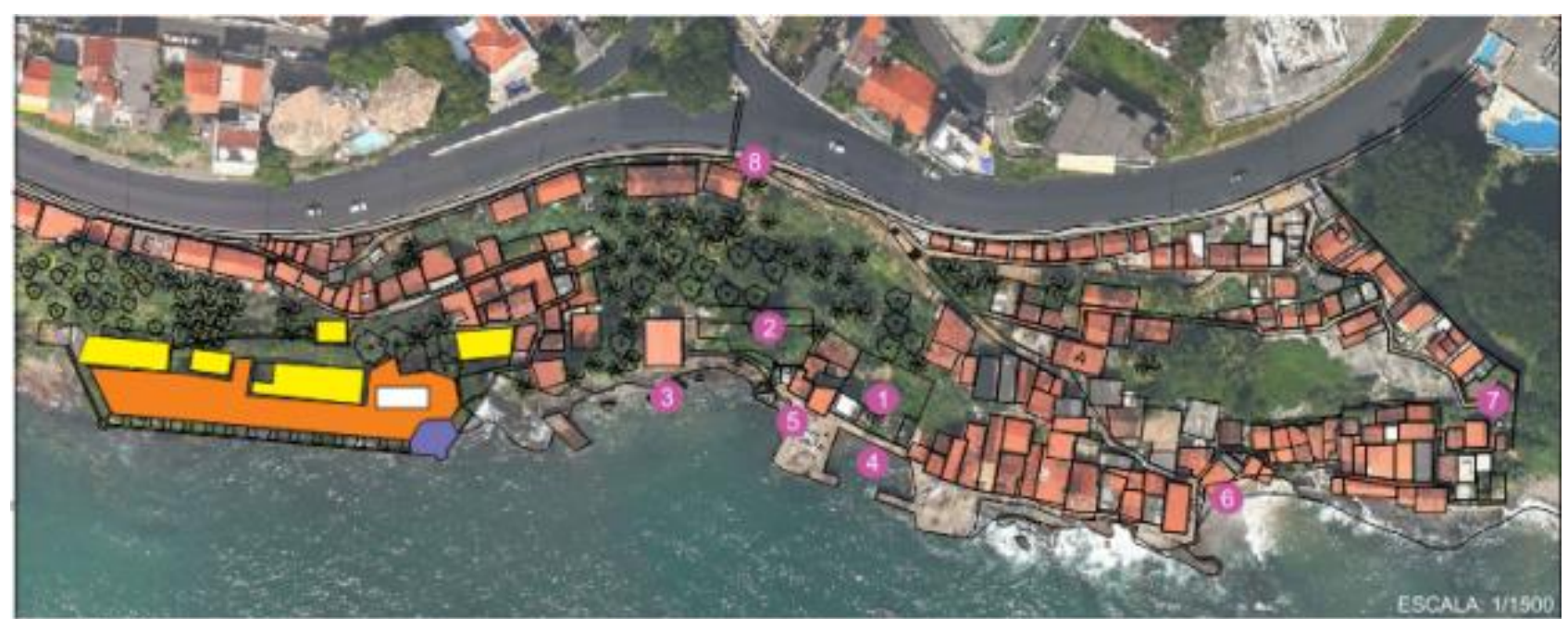

Legendr

(1) AREA DO ANTIGO TRAPICHE

(2) ÁREA DE ANMGA EDEACAÇÂAO

(3) ANMCO OUEBRA MAR / PASSAREIA

(4) PIER / ÁREA DE BARES

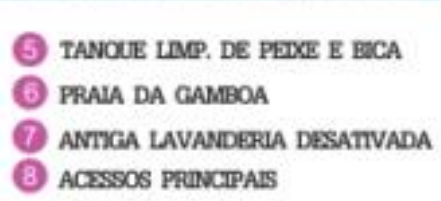

AREAS DE MORADIA NO FORTE DE SP AREA LIVRE UTHIZADA PEAA COMUNIDADE LOCAL. DO PALCO DE FESTAS LOCASS ESPACO DE LAZTR RNAMTLL.

Fonte: Elaboração do autor do projeto (ZANOLI, 2015), GOOGLE. Base Google Earth. Version 7. Salvador-BA. 


\section{Projeto de habitação de interesse social como instrumento de luta e conquista}

A constante negativa dos órgãos públicos sobre a realocação dos moradores do Forte na comunidade e a incapacidade técnica dos moradores para rebater e propor alternativas contribuíram para uma letargia na implementação de medidas para proteção patrimonial e a consequente melhoria habitacional da comunidade. A apresentação de um estudo viável para tal demanda, respeitando as expectativas de moradores ocupantes do Forte e da comunidade, foi importante para mobilização e discussão de uma possível solução.

Os terrenos vagos apresentados pela associação comunitária como possibilidade de projeto se localizam em frente ao píer existente. O terreno identificado como 01 se localiza no alto da ocupação e tem seu acesso por escadarias. É formado por dois platôs de aproximadamente $30 \times 7$ metros. Há um muro de arrimo, algumas mangueiras e resquícios de fundações. $O$ terreno 02 , em cota mais baixa, com aproximadamente 20x18metros, é plano e cercado por paredões de pedra, com algumas fundações e dois pilares em tijolo maciço, que provavelmente sustentaram o telhado de um antigo galpão. Nesse terreno há uma edificação de dois pavimentos, utilizada por pescadores para a produção de barcos e redes, nesta época sem uso como moradia.

Figura 5: Áreas livres identificadas para o projeto

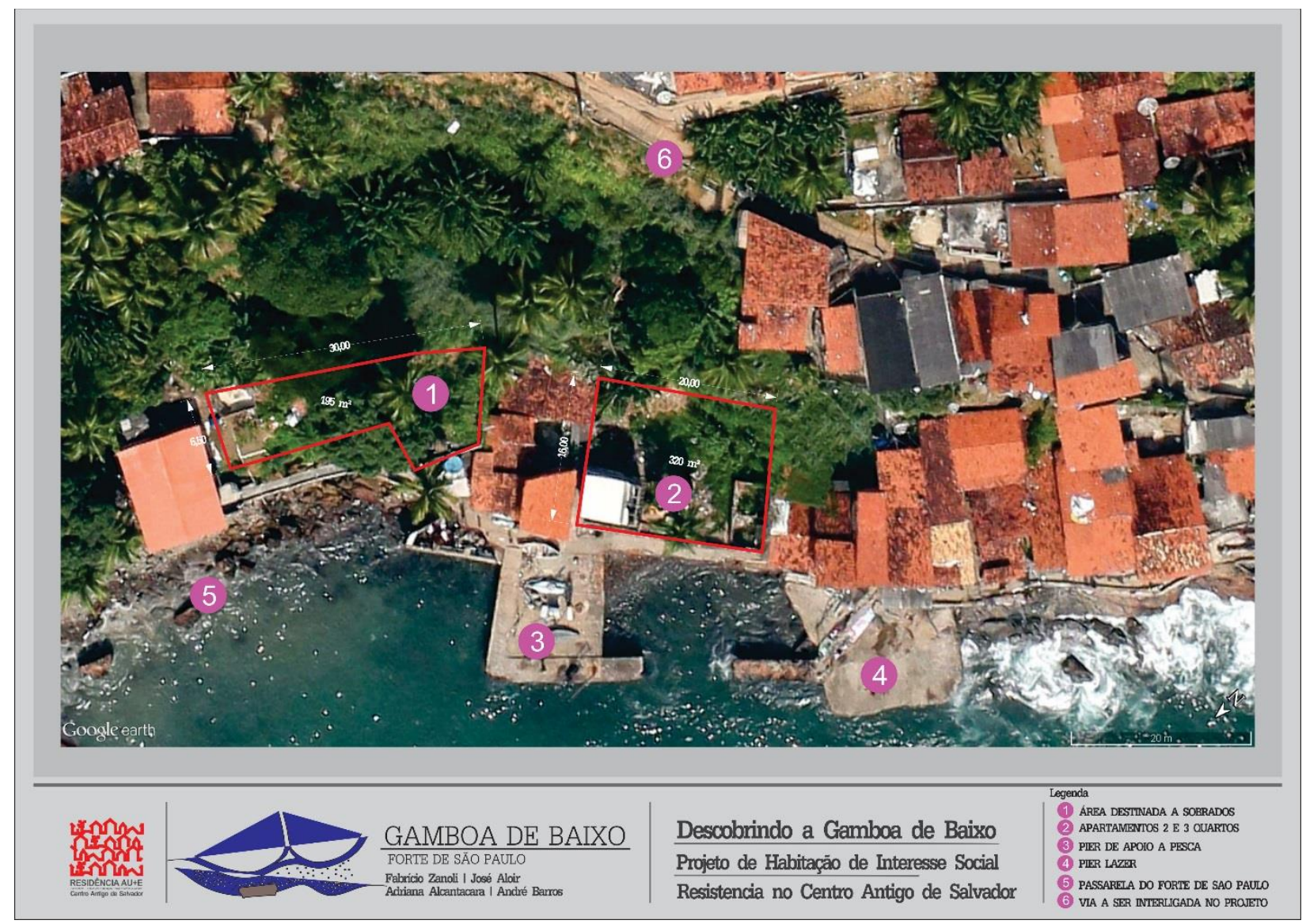

Fonte: Elaboração do autor do projeto (ZANOLI, 2015), GOOGLE. Base Google Earth. Version 7. Salvador-BA.

O estudo originalmente contemplava dezoito famílias, mas por restrições de gabarito, respeito ao conjunto tombado, a paisagem da encosta e a dimensão do terreno, esse número foi reduzido para treze famílias. A Associação de moradores articulou, como solução para a falta de três dessas futuras moradias, a ampliação de casas de familiares dos moradores do Forte, localizadas na comunidade, garantindo a permanência de todas as famílias nessa localidade. Neste projeto de assessoria também foram levantados os imóveis desocupados, assim como casas de aluguel na comunidade, com alternativa complementar.

Considerou-se as possibilidades de financiamento, seguindo os parâmetros do Programa Minha Casa Minha Vida Entidades, já que a construção por autogestão ou mutirão é de praxe na Gamboa.

O programa do projeto para o terreno 01 foi definido com base nas demandas dos moradores, resultando em nove unidades de habitações, pátio interno para as atividades coletivas e instalação da Associação de 
Pescadores. Para esse terreno foram projetados quatro blocos de apartamentos de dois quartos, sala, banheiro e cozinha, com um total de $52 \mathrm{~m}^{2}$. Dois blocos possuem dois pavimentos e os demais, três pavimentos. As unidades são interligadas por passarelas em estrutura metálica e placas de concreto no piso. O volume respeita a escala local, recompondo a unidade paisagística e patrimonial.

Figura 6: Planta tipo das habitações

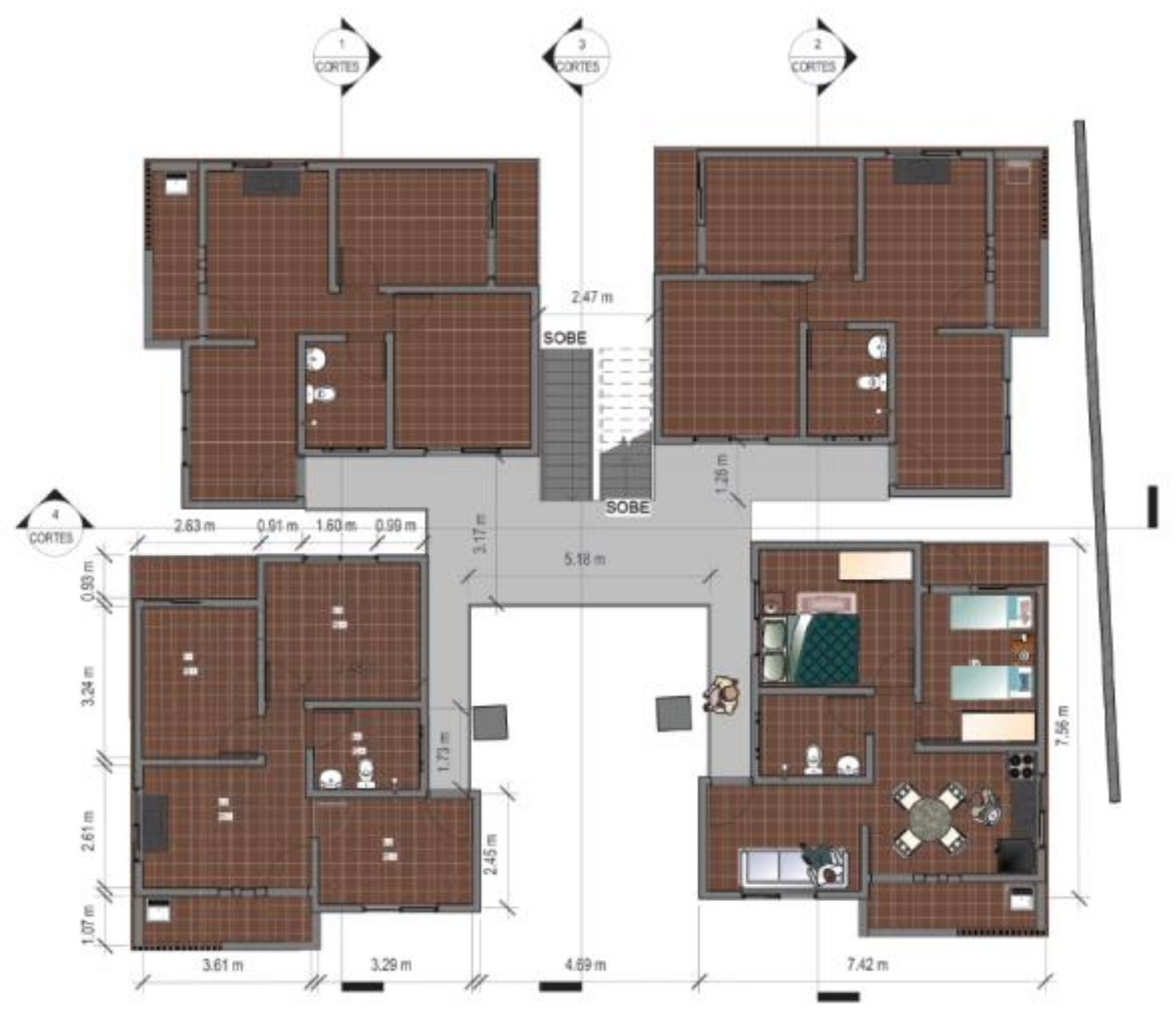

Fonte: Elaboração do autor do projeto (ZANOLI, 2015)

As passarelas que ligam as edificações têm por objetivo, além de acesso, recriar o espaço de convívio entre os moradores, sendo abertas e interligadas com o pátio principal e com vista para o mar. Na cota mais alta, ligam-se a uma das principais vias da comunidade. Pensando na melhoria da acessibilidade, foi criada também uma ligação entre os dois terrenos, através da passarela sobre o muro de arrimo.

O terreno 02 comporta quatro sobrados de dois pavimentos, o que soma um total de 13 novas moradias para relocação das famílias do Forte. As edificações nesse terreno foram locadas nos platôs, respeitando-se a topografia local e o ambiente natural, com um total de $45 \mathrm{~m}^{2}$, por unidade habitacional. $\mathrm{O}$ projeto considera as árvores dos terrenos, assim como uma fonte de água, protegida por arco de pedra, que provavelmente data da época de construção do Forte. A disposição dos blocos cria pátios de integração, seguindo o mesmo conceito.

O escopo do projeto foi ampliado, englobando as áreas públicas de entorno, indicando as possíveis intervenções para o sucesso da realocação, como o redesenho do quebra mar ligando toda a comunidade pela orla. O projeto, indicou também a reestruturação do píer de pesca, que se encontra sem atracadouro ou 
rampa, itens necessários para um melhor funcionamento das atividades pesqueiras na comunidade e a subsistência dos moradores.

Figura 7: Perspectiva do projeto das novas habitações e espaço público

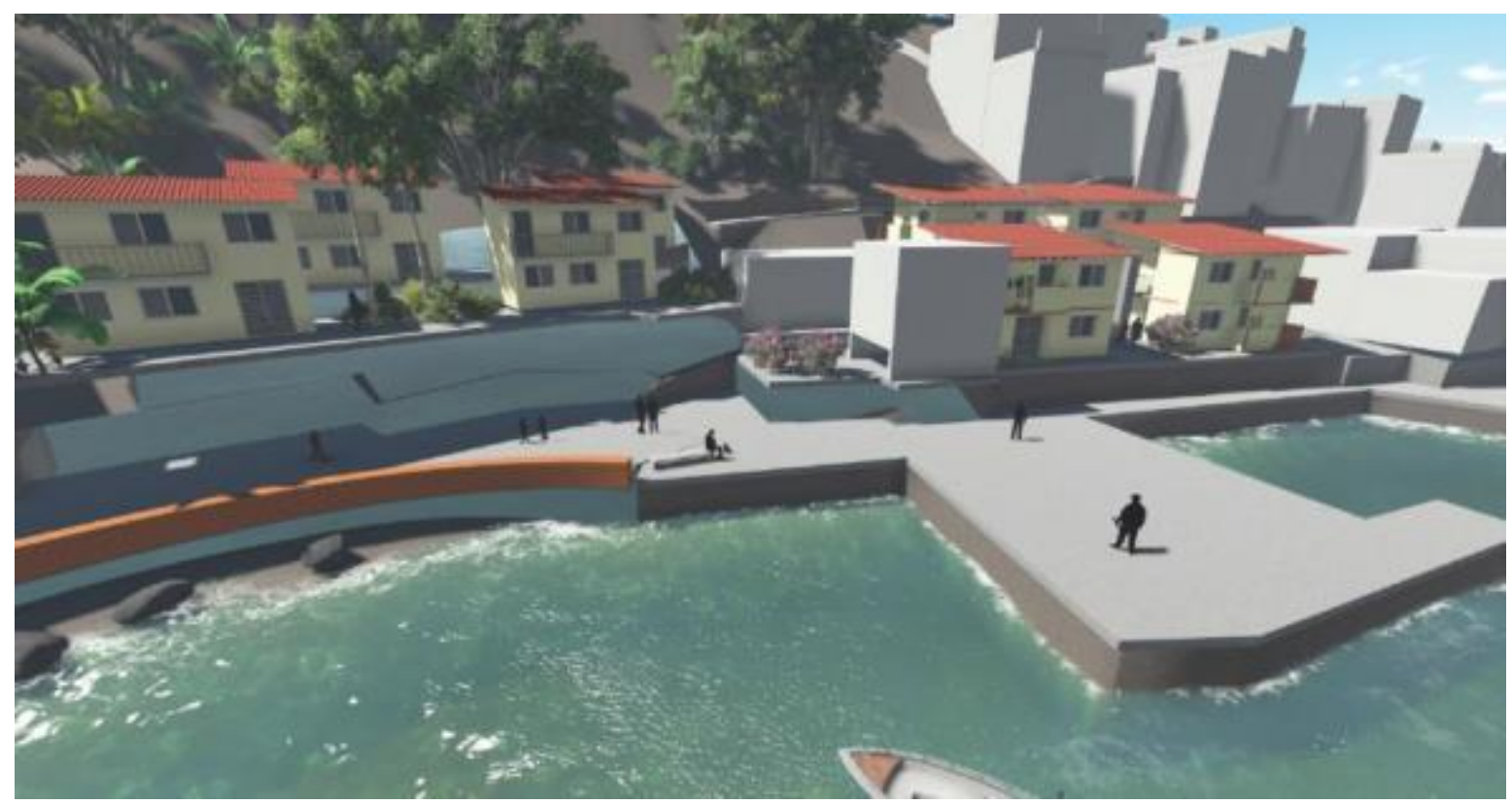

Fonte: Elaboração do autor do projeto (ZANOLI, 2015).

Figura 8: Cortes de elevação, do projeto dos blocos de unidades
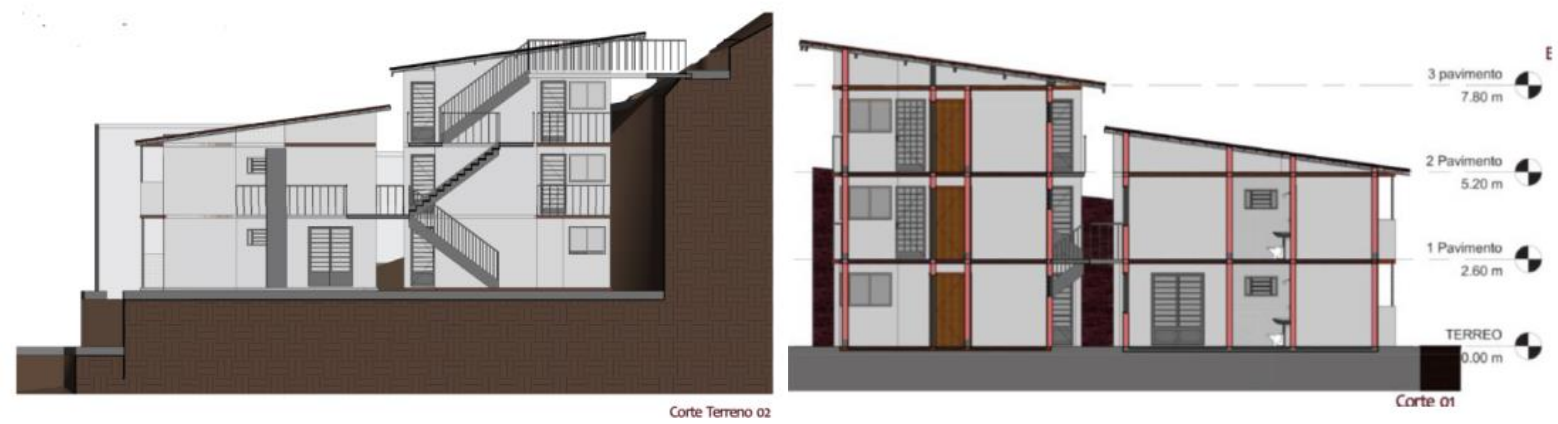

Fonte: Elaboração do autor do projeto (ZANOLI, 2015).

\section{ASSISTÊNCIA TÉCNICA CONTINUADA, DESAFIOS E CONQUISTAS}

Ao final do processo de assistência técnica, esse contou com diversas reuniões em órgãos públicos relacionados a essa área e resultou em visitas técnicas para avaliar a atual condição do bairro e da localidade. Foram traçados planos para retomada da discussão de regularização fundiária, tal qual iniciada pela Prefeitura de Salvador em 2007, por meio da antiga Secretaria de Habitação - SEHAB, ação paralisada em 2008, com a extinção dessa secretaria. Com a certeza de possibilidade de realocação das famílias do Forte na própria comunidade, como demonstra o projeto apresentado, alguns avanços foram conquistados. A Associação passou a fazer parte, a convite da SPU, do Grupo de Trabalho que discute a cessão de áreas federais para fins habitacionais.

Entre os produtos alcançados pela Residência Profissional em conjunto com a comunidade, considera-se como maior ganho para ambas as partes, as capacitações, os contatos e parcerias, além da cessão dos projetos à comunidade pelo autor por meio dessa atuação da UFBA. Os processos desenvolvidos com os moradores foram extremamente engrandecedores e permitiram o empoderamento da comunidade e dos Residentes na conquista pelo direito à cidade. 
Destaca-se ainda, nesse processo, que a comunidade foi inserida no Google Maps, minimizando a sua "invisibilidade" como destacado pela Associação de Moradores. Foi elaborado um relatório sobre os problemas urbanos aí identificados pelos residentes e moradores, no intuito de ser encaminhado aos órgãos responsáveis pela infraestrutura urbana. A organização do acervo é outro produto desse trabalho, com a descrição dos documentos encontrados como escrituras públicas e Termo de Cessão de área pelo SPU ao Município, além de cópia do processo do MPF. O projeto básico de arquitetura para relocação das famílias, apresentado em prancha técnica e volumetria 3D também foi finalizado e repassado a comunidade, na expectativa de financiamento para o desenvolvimento do projeto executivo.

A assistência técnica iniciada nesse curso de especialização continua de forma voluntária pela equipe atuante, com novos apoios de outros militantes do movimento social, fortalecendo, assim, a assessoria à comunidade para instrumentalizar a luta pelo direito à cidade, seguindo com novas conquistas.

\section{REFERÊNCIAS}

ARAÚJO NETO, J. A. C. Regularização Fundiária: C.U.E.M. como instrumento de resistência e permanência da Gamboa de Baixo. Trabalho Final do Curso de Especialização Assistência Técnica, Habitação e Direito à Cidade. Salvador, PPGAU-UFBA, jan.2015.

BRASIL. Estatuto da Cidade. Lei Federal no 10.257, de 10 de julho de 2001. Instituto POLIS, 3ª edição. Brasília. 2005.

GORDILHO-SOUZA, Angela Maria. Limites do habitar: segregação e exclusão na configuração urbana contemporânea de Salvador e perspectivas no final do século XX". Salvador: EDUFBA, 2a . edição revista e ampliada, 2008 (original de 1999).

LEFEBVRE, Henri. O Direito à Cidade. 1ํㅡㄹ. ed. São Paulo: Moraes, 1991.

OLIVEIRA, Mário Mendonça de. As fortificações portuguesas de Salvador quando Cabeça do Brasil. Salvador: Omar G / Fundação Gregório de Mattos, 2004. v. 1. 264p

PERRY, Keisha-Khan Y. ; CAMINHA, Ana Cristina da Silva "DAQUI NÃO SAIO, DAQUI NINGUÉM ME TIRA": PODER E POLÍTICA DAS MULHERES NEGRAS DA GAMBOA DE BAIXO, SALVADOR. Revista Gênero-UFF, Niterói, v. 9, n. 1, p. 127-153, 2. sem. 2008

PORTELA, Rafael Davis. Pescadores na Bahia do Século XIX. 127 f. : il. Universidade Federal da Bahia Dissertação de Mestrado. Salvador, 2012.

PREFEITURA MUNICIPAL DE SALVADOR. Plano Municipal de Habitação de Salvador (2008-2025). Salvador: SEHAB/PMS, 2008.

SANTOS, Carlos Nelson F. dos (coord). Quando a rua vira casa. 3aㅡ ed. São Paulo: ed. Projeto, 1985

ZANOLI, Fabrício O. Projeto de realocação dos moradores do Forte de São Paulo - Salvador/BA, Trabalho Final do Curso de Especialização Assistência Técnica, Habitação e Direito à Cidade. Salvador, PPGAU-UFBA, jan.2015.

ZANOLI, Fabrício O. Ação Patrimonial, ocupação popular e os conflitos da preservação: o caso da comunidade da Gamboa de Baixo em Salvador-BA. Dissertação (mestrado) - Faculdade de Arquitetura - Universidade Federal da Bahia, Programa de Pós-Graduação em Arquitetura e Urbanismo, 2017.

\section{NOTAS}

${ }^{1}$ CONDER- Companhia de Desenvolvimento Urbano do Estado da Bahia.

${ }^{2}$ Programa de Aceleração do Crescimento-PAC, do Governo Federal. Etapa voltada a núcleos de centro históricos.

3 O trabalho na comunidade foi desenvolvido de fevereiro a outubro de 2014. Este texto tem como base o Trabalho Final apresentado pelo autor do projeto, em janeiro de 2015, no Curso de Especialização Assistência Técnica, Habitação e Direito a Cidade, na modalidade Residência Profissional em Arquitetura, Urbanismo e Engenharia, da Universidade Federal da Bahia (ZANOLI, 2015), tendo como tutora a Profa. Any Ivo. Traz contribuições da equipe que atuou na área, composta pelo autor e pelo urbanista José Aloir Araújo Neto, bem como levantamentos que embasaram a conceituação do projeto apresentado.

${ }^{4}$ O projeto sofreu pequenas alterações devido a modificações no terreno em 2016, para a Fundação Mario Leal Ferreira, órgão executor de projetos da Prefeitura de Salvador, visando a contratação do mesmo para execução.

NOTA DO EDITOR $\left({ }^{*}\right)$ O conteúdo do artigo e as imagens nele publicadas são de responsabilidade do(s) autor(es). 